\title{
The relationship between oral hygiene level and gingivitis in children
}

\author{
Tamara Pawlaczyk-Kamieńska ${ }^{\mathrm{B}-\mathrm{E}}$, Natalia Torlińska-Walkowiak ${ }^{\mathrm{B}-\mathrm{E}}$, Maria Borysewicz-Lewicka ${ }^{\mathrm{A}, \mathrm{E}, \mathrm{F}}$ \\ Department of Pediatric Dentistry, Poznan University of Medical Sciences, Poland \\ A - research concept and design; $B$ - collection and/or assembly of data; $C$ - data analysis and interpretation; \\ $\mathrm{D}$ - writing the article; $\mathrm{E}$ - critical revision of the article; $\mathrm{F}$ - final approval of the article
}

\section{Address for correspondence \\ Tamara Pawlaczyk-Kamieńska}

E-mail: tamara_pawlaczyk@wp.pl

\section{Funding sources}

None declared

\section{Conflict of interest}

None declared

Received on January 9, 2017

Reviewed on January 17, 2017

Accepted on April 12, 2017

\begin{abstract}
Background. The condition of the teeth, periodontium and oral mucosa determines directly and indirectly the general health of the organism and, therefore, requires to be monitored. Childhood, especially the first years of life, is the time when proper health-promoting behaviors are formed, allowing the future prevention of such diseases as dental decay and gingivitis. Studies concerning the gingival status and bleeding in children are scarce, although such knowledge can be useful in planning preventive programs.
\end{abstract}

Objectives. The aim of the study was to determine the relationship between oral hygiene level and the likelihood of gingival bleeding.

Material and methods. The examined group comprised 2856 children aged 7 years, living in an urban area in western Poland. The hygiene status was evaluated according to the simplified Debris Index (DI-S) criteria and the periodontal status was evaluated according to the Community Periodontal Index (CPI) criteria. Logistic regression analysis was used to determine the predictors of gingival bleeding.

Results. The average value of DI-S was 0.91 ; it was not significantly different between girls and boys. In more than a half of the studied subjects (59.10\%), oral hygiene was fair, in 12.46\% - poor. Clinically healthy periodontium was observed in $91.32 \%$ of cases, bleeding on probing was present in $7.46 \%$ of cases. Calculus was detected in 1.22\% of the children. Logistic regression analysis of the predictors of gingival bleeding showed that children with fair and poor oral hygiene were respectively 6 and 25 times more likely to show bleeding on probing compared to the children with very good oral hygiene.

Conclusions. In the studied group, it was noted that there is a need to promote oral hygiene, as it contributes to the fall in gingivitis prevalence among schoolchildren.

Key words: gingivitis, oral hygiene, Polish children

DOI

10.17219/acem/70417

\section{Copyright}

Copyright by Author(s)

This is an article distributed under the terms of the

Creative Commons Attribution Non-Commercial License

(http://creativecommons.org/licenses/by-nc-nd/4.0/) 


\section{Introduction}

The condition of the teeth, periodontium and oral mucosa determines directly and indirectly the general health of the organism and, therefore, requires to be monitored. Epidemiological studies indicate that in children and adolescents the most often observed gingivitis is dental plaque-induced gingivitis, which is a reversible and nondestructive form of periodontal disease., ${ }^{1,2}$ Poor oral hygiene and the accumulation of bacterial plaque is a known and important predisposing factor of gingivitis. However, the prevalence of destructive forms of periodontal disease is lower in young individuals than in adults. Still, dental plaque accumulation in childhood and adolescence can be associated with the development of periodontal disease in later life. ${ }^{3}$ Children with healthy gingival tissues most likely progress to adult life with good periodontal health. Therefore, the key concern is periodontal health and good oral hygiene in childhood. ${ }^{1-5}$

Childhood, especially the first years of life, is the time when proper health-promoting behaviors are formed, allowing the future prevention of such diseases as dental decay and gingivitis. A fundamental element of prevention are effective daily prophylactic-hygienic procedures to remove dental plaque. Studies concerning the gingival status and bleeding in children are scarce, although such knowledge can be useful in planning preventive programs.

The aim of the study was to evaluate the hygiene and periodontal status among children living in an urban area in western Poland, and to determine the relationship between oral hygiene and the likelihood of gingival bleeding.

\section{Material and methods}

A total of 2856 generally healthy 7-year-olds entered the study (1408 girls and 1448 boys), representing $70 \%$ of the population attending the $1^{\text {st }}$ year of elementary public schools in Poznań (about 550,000 inhabitants), Poland. The schools were randomly selected; all 7-year-old children who were at school on the days of examination were examined. Children with medically compromising conditions which could affect periodontal health were excluded from the study. Parents or caregivers were asked to sign a written statement of consent for their child's participation in the study. The studies were performed in the morning (9-11 a.m.). In order to minimize extra brushing efforts, the children were not informed in advance about the exact date of the oral examination.

The oral hygiene status was assessed using the simplified Debris Index (DI-S) of Green and Vermillon. ${ }^{6}$ The teeth were examined as recommended by the index (the labial surfaces of teeth $11,16,26$, and 31, and the lingual surfaces of teeth 36 and 46). The criteria for classifying DI-S scores of 0-3 were as follows: oral cleanliness was considered "very good" if the DI-S score was $\leq 0.2$; "good" if the DI-S score was 0.3-0.6; "fair" when it showed 0.7-1.8; and "poor" when the score ranged between 1.9 and 3.0. ${ }^{6}$

The periodontal status was assessed using the Community Periodontal Index (CPI) according to the World Health Organization (WHO) basic methods of oral health surveys. ${ }^{7}$ Recording of CPI was done in accordance with the WHO guidelines for the population group under 15 years of age. To avoid recording false pockets, which are common around erupting teeth, 3 codes were used: code 0 - healthy (no bleeding on probing and no calculus); code 1 - bleeding on probing (no calculus); code 2 - dental calculus present. The evaluation was performed on 6 index teeth (teeth 16, 11, 26, 36, 31, 46). According to the WHO classification, the highest CPI code was applied. ${ }^{8,9}$

The oral cavity was examined by pediatric dentists in the school nurse consultation room, under artificial light, using a dental mirror and a probe, according to the recommendations for oral epidemiological surveys by the WHO.? The same test conditions were kept for all examined children. The practitioners were calibrated prior to the study in order to control reliability. Calibration was performed by the clinical examination of children who were not included in the study. The kappa value was 0.85 for the oral hygiene status and 0.8 for the periodontal status, thus representing a satisfactory level of concordance. The obtained data was recorded in specially designed charts.

The statistical analyses were performed using STATISTICA v. 12 (StatSoft Inc., Tulsa, USA) and CytelStudio v. 10.0 (StatXact, Cambridge, USA) programs. Average values for quantitative data and the percentage for category data were determined. The $X^{2}$ test was used to determine whether gender is related to the CPI value, oral cleanliness (the DI-S value) and bleeding, as well as whether bleeding is related to DI-S. Logistic regression analysis was used to identify independent risk factors, such as gender and oral hygiene (DI-S) for gingival bleeding (present or absent) expressed in odds ratios (OR) and 95\% confidence intervals (CI). The level of significance was set at 0.05 (Fig. 1).

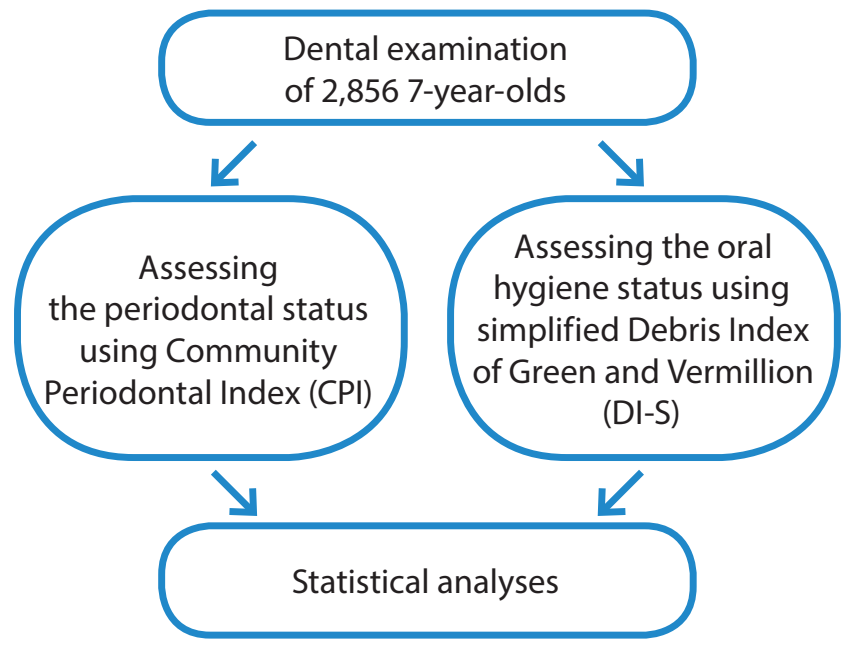

Fig. 1. Methodology of the study 
The study was reviewed and approved by the Ethics Committee at Poznan University of Medical Sciences, Poland; it has been conducted in full accordance with the World Medical Association Declaration of Helsinki (No. 466/10).

\section{Results}

The average DI-S value in the studied group was 0.91 and it was not significantly statistically different in girls (DI-S $=0.87$ ) and in boys (DI-S = 0.95). Very good oral hygiene was noted in $23.14 \%$ of the children, fair oral hygiene in more than a half $(59.10 \%)$ of the studied group and poor in $12.46 \%$ of the children. No statistically significant dependence was observed between the distribution of the oral hygiene status and gender $(\mathrm{p}=0.066)$ (Table 1$)$.

Table 1. Oral hygiene status (DI-S)

\begin{tabular}{|c|c|c|c|}
\hline Score & Female [\%] & Male [\%] & Total [\%] \\
\hline $0.0-0.2$ & 24.86 & 21.4 & 23.14 \\
\hline $0.3-0.6$ & 5.40 & 5.18 & 5.28 \\
\hline $0.7-1.8$ & 58.52 & 59.67 & 59.10 \\
\hline $1.9-3.0$ & 11.22 & 13.67 & 12.46 \\
\hline
\end{tabular}

DI-S - simplified Debris Index.

Clinically healthy periodontium was observed in $91.32 \%$ of the studied children. Bleeding on probing was present in $7.46 \%$ of cases and supragingival dental calculus in $1.22 \%$ of cases. Statistical analysis did not show a dependence between the CPI value and gender $(\mathrm{p}=0.669)$ (Table 2).

Table 2. Periodontal status (CPI)

\begin{tabular}{|c|c|c|c|}
\hline Score [\%] & Female [\%] & Male [\%] & Total [\%] \\
\hline 0 & 91.55 & 91.09 & 91.32 \\
\hline 1 & 7.31 & 7.60 & 7.46 \\
\hline 2 & 1.14 & 1.31 & 1.22 \\
\hline
\end{tabular}

CPI - Community Periodontal Index.

A statistical analysis performed using the $\chi^{2}$ test confirmed a dependence between bleeding and the oral hygiene status $(\mathrm{p}<0.0001)$. Among those children who showed bleeding, only $3.76 \%$ presented very good oral hygiene on the day of the examination and $2.35 \%$ presented good oral hygiene. However, in more than a half of them (54.93\%), hygiene was classified as fair, and in $38.96 \%$ as poor.

Gender was not significantly associated with gingival bleeding. Therefore, in this model, the only significant variable was a range of the DI-S values $(\mathrm{p}<0.0001)$. Logistic regression analysis of the predictors of gingival bleeding showed that children with poor oral hygiene were 4 times more likely to have gingival bleeding compared to children with fair oral hygiene ( $\mathrm{p}<0.0001$; OR: 4.0; 95\% CI:
2.95-5.61). Furthermore, children with fair and poor oral hygiene were respectively 6 ( $\mathrm{p}<0.0001$; OR: 6.08; 95\% CI: 2.96-14.49) and 25 (p < 0.0001; OR: 24.82; 95\% CI: 11.77-60.02) times more likely to have bleeding on probing compared to children with very good oral hygiene. There was no significant dependence between very good and good hygiene $(\mathrm{p}=0.15)$ (Table 3$)$.

Table 3. Logistic regression output with regard to the predictors of bleeding on probing

\begin{tabular}{|l|c|c|c|}
\multicolumn{1}{|c|}{ Predictor } & OR & $95 \%$ Cl & p-value \\
\hline \multicolumn{4}{|c|}{ hygiene leve* (DI-S) } \\
\hline Good (0.3-0.6) & 2.80 & $0.71-9.83$ & 0.150 \\
\hline Fair (0.7-1.8) & 6.08 & $2.96-14.49$ & $<0.0001$ \\
\hline Poor (1.9-3.0) & 24.82 & $11.77-60.02$ & $<0.0001$ \\
\hline
\end{tabular}

Predictors of bleeding on probing were determined as present vs absent; OR - odds ratio; Cl - confidence interval; DI-S - simplified Debris Index; * reference category: very good oral hygiene level (DI-S $\leq 0.2)$.

\section{Discussion}

Dental literature reports concerning oral hygiene in early school children are scarce. In Poland, children start compulsory education at 7 years of age. At this age, the first permanent teeth usually erupt. Therefore, this age seems to be the best to evaluate oral hygiene and the periodontal status in children.

In the studies carried out among children in Iran, the average DI-S value was 1.19, among children from Minsk (Belarus) it was 1.64, and in Kuwait, the DI-S value was $1.5 .1,10,11$ Moreover, the inclusion of gender data into the study provided a conclusion that oral hygiene in boys was significantly better than in girls. ${ }^{11}$ In the quoted publications, the average value of DI-S showed worse oral hygiene than in the studied population of western Poland, where it was 0.91 for the population, with similar values for boys and girls.

Numerous epidemiological studies show similar oral hygiene status in children all over the world. In the studies by de Almeida et al., 799 Portuguese 6-year-olds were examined for oral hygiene, of which $7.6 \%$ showed very good oral hygiene status; good oral hygiene status was present in $16.5 \%$, fair in $72.6 \%$ and poor in $3.3 \%$ of the studied children. ${ }^{12}$ On the other hand, Al-Mutawa et al. did not note very good oral hygiene in the group of 3294 children - the DI-S value in that case was below 0.3. In the majority of the studied population (67\%), oral hygiene was assessed as fair, and in $29.1 \%$ of cases - as poor. ${ }^{11}$ Krishnam et al. evaluated oral hygiene in 5129 children, aged $5-12$ years, of the Eastern Ghats region of southern India, using the simplified oral hygiene index (OHI-S) by Green and Vermillion (good: 0.0-1.2; fair: 1.2-3.0; poor: 3.1-6.0). ${ }^{13}$ Good oral hygiene was present in $34.27 \%$ of the children, $50.98 \%$ showed fair hygiene status and $14.7 \%$ were evaluated as having poor oral hygiene. Anupriya et al. evaluated 
oral hygiene using the OHI-S in 1787 5-8-year-olds of Himachal Pradesh in the northern India. ${ }^{14}$ Good hygiene was noted in $9.4 \%$, fair in $63.6 \%$, and poor in $26.8 \%$ of cases. In our own studies, similarly to other authors', the most numerous group of patients consisted of the students presenting fair oral hygiene status (59.1\%).

The literature concerning the periodontal status in 7-year-old children presents varied results. The percentage of healthy periodontium at that age ranges between 9\% and 80\%. ${ }^{5,14-16}$ Składnik-Jankowska and Kaczmarek evaluated the periodontal status of 7-year-olds from southern Poland and found healthy periodontium in $80 \%$ of them, with no statistically significant difference between genders. ${ }^{15}$ A relatively high percentage of children with healthy periodontium (70.43\%) was observed by Varas et al. in children aged 6-8 years (Santiago Metropolitan Region in Chile), while markedly lower values $-22.5 \%$ - were reported by Dini et al. in Brazilian 7-year-olds. ${ }^{5,16} \mathrm{~A}$ still lower percentage was noted by Anupriya et al.: in only $9.4 \%$ of the children aged 5-8 years. ${ }^{14}$ Our own studies showed healthy periodontium to be present in $91.32 \%$ of the studied population of the 7-year-olds from a big city. Similarly to the quoted findings of other authors, no statistically significant difference was found here between girls and boys.

Different values concerning bleeding are reported in some other studies. In the paper by Składnik-Jankowska and Kaczmarek, bleeding on probing was present in $14.5 \%$ of the 7-year-olds and this value was nearly 2 times higher than that obtained in our own studies (7.46\%). Still higher values were quoted by Varas et al., A nupriya et al. and Dini et al., who observed gingival bleeding in $27.49 \%, 71.9 \%$ and $76.8 \%$ of children, respectively. ${ }^{5,14,16}$

Contrary to our study, in the research by Arnlaugsson and Magnusson, as well as Hemadneh and Ayesh, the gingival bleeding index (GBI) was used. ${ }^{2,4}$ Among Icelandic 6-yearolds of Reykjavik examined by Arnlaugsson and Magnusson, healthy gums were noted in $26 \%$ of the children. ${ }^{2}$ Similar values were obtained by Hemadneh and Ayesh in Jordanian children, out of whom $30.6 \%$ had healthy gums. ${ }^{4}$ However, the studies by Bossnjak et al., comprising Croatian children aged 6-11 years, revealed that healthy gums were present in $43 \%$ of the studied subjects. ${ }^{17}$ In the quoted studies, as well as in our own ones, there were no statistically significant differences between girls and boys.

Dental calculus occurs less often in children than in adults. In adolescent patients, supragingival deposit is mainly present. Składnik-Jankowska and Kaczmarek and Varas et al. noted this deposit in a small percentage of the examined children, $4 \%$ and $2.08 \%$, respectively. ${ }^{5,15}$ A higher percentage was reported by Anupriya et al. in 5-8-year-old Indian children and Varenne et al. in 6-year-old African children $-10.2 \%$ and $58 \%$, respectively. ${ }^{14,18}$

Based on epidemiological studies performed in Poland in 1987 and 1995, Banach compared the prevalence of dental calculus among 7 - and 12-year-olds. ${ }^{19}$ The percentage of Polish 7-year-olds with dental calculus dropped from
$3.1 \%$ to $0.6 \%$ over 8 years, and the values for 12 -year-olds decreased from $33.4 \%$ to $21 \% .{ }^{19}$ In the studies by Chłapowska, carried out in the city of Poznan in 1995, dental calculus was observed in $3.7 \%$ of children aged 7 years and in $26.7 \%$ of those aged 12 years. ${ }^{20}$ However, in the study undertaken 4 years later by Pawlaczyk-Kamieńska, which included 521 children aged 12 years from the same area (Poznań), dental calculus was found in $26.3 \%$ of the children. ${ }^{21}$ In the same educational setting of Poznań, 20 years after the study made by Chłapowska, dental calculus was noted in $1.22 \%$ of children aged 7 years. The presented data displays a drop in the percentage of children with dental calculus from $3.7 \%$ to $1.22 \% .^{20,21}$ Moreover, the data confirms the former reports of an increase in the percentage of people with dental calculus along with their age.

The statistical analysis of our own results did not reveal any correlation between gender and bleeding, although the research done by Gopinath et al. showed that males were 2.11 times more likely to develop gingivitis than females. ${ }^{22}$ However, in our study, a correlation was found between the amount of bacterial plaque and the likelihood of bleeding, which confirms a relationship of gingivitis etiology and the oral hygiene status. In children with poor oral hygiene, the likelihood of bleeding on probing was 4 times higher than in children with fair oral hygiene. When children with fair oral hygiene were compared to those with very good hygiene, it was revealed that the likelihood of bleeding was 6 times higher in the fair oral hygiene group. Still, the children with poor hygiene were 25 times more likely to develop bleeding on probing than those with a very good hygiene status. In $71.56 \%$ of the studied 7-year-old children living in Poznań, oral hygiene was evaluated as fair (59.1\%) or poor (12.46\%). Therefore, they have a 6 or 25 times lower chance to maintain healthy periodontium in the future, compared to their counterparts showing very good hygiene $(23.14 \%$ of the children). The study proved a correlation between the oral hygiene status and gingival bleeding. Therefore, an improvement of daily hygienic procedures to remove bacterial dental plaque seems of greatest importance in reducing the likelihood of periodontal disease in adult age.

Epidemiological studies provide the necessary knowledge to formulate and implement programs of prophylaxis, which will bring about an improvement of oral health. It seems that the provision of dental education to children with mixed dentition should also be a priority in order to teach better skills of bacterial plaque removal.

Limitations of our study comprise the sample size and participants. It might be possible that children with poor oral hygiene were not given the consent for the examination to avoid any unpleasant comments. Furthermore, some children probably did not participate in the research because of strong dental fear. We also did not study the socioeconomic status and educational level of the subjects, which could have led to a deeper analysis. Nevertheless, we believe that our findings closely represent the population values. 


\section{Conclusions}

Among the examined children living in a big city, the majority show fair or poor oral hygiene.

Unsatisfactory oral hygiene status significantly increases the likelihood of bleeding on probing. The performed study has shown the need to treat and prevent periodontal pathologies. Therefore, the implementation of educational programs to improve oral health promoting behaviors seems necessary.

\section{References}

1. Leous $P$, Palianskaya L, Leous L. Oral hygiene and gingival inflammation in 6-8-year-olds from a junior school in Minsk who participated in a supervised oral hygiene programme. Oral Health Dent Manag. 2009;7:27-30

2. Arnlaugsson $S$, Magnusson TE. Prevalence of gingivitis in 6-yearolds in Reykjavik, Iceland. Acta Odontol Scand. 1996;54(4):247-250.

3. Albandar JM. Global risk factors and risk indicators for periodontal diseases. Periodontol 2000. 2002;29:177-206.

4. Hemadneh S, Ayesh D. Prevalence of gingivitis in 6-7 year old Jordanian children. Pakistan Oral \& Dental Journal. 2011;31:168-170.

5. Varas F, Zillmann G, Munoz A, et al. Periodontal status and treatment needs of children from 6 to 8 years old in the Santiago Metropolitan Region of Chile. J Oral Res. 2011;26:10-15.

6. Green JC, Vermillon JR. The simplified oral hygiene index. JADA. 1964;68:7-13.

7. World Health Organization. Oral Health Surveys, Basic Methods. $4^{\text {th }}$ ed. Geneva, Switzerland: World Health Organization; 1998:1-67.

8. Clerehugh V, Tugnait A. Diagnosis and management of periodontal diseases in children and adolescents. Periodontol 2000. 2001;26:146-168.

9. Ainamo J, Barmes D, Beagrie G, Cutress T, Martinn J, Sardo-Infirri J. Development of the World Health Organization (WHO) Community Periodontal Index of Treatment Needs (CPITN). Int Dent $J$. 1982;32(3):281-291.
10. Shaghaghian S, Bahmani M, Amin M. Impact of oral hygiene on oral health-related quality of life of preschool children. Int J Dent Hyg. 2015;13(3):192-198.

11. Al-Mutawa SA, Shyama M, Al-Duwairi Y, Soparkar P. Oral hygiene status of Kuwaiti schoolchildren. East Mediterr Health J. 2011:17(5):387-391.

12. de Almeida C, Petersen P, Andre S, Toscano A. Changing oral health status of 6 -and 12 -years-old schoolchildren in Portugal. Community Dent Health. 2003;20(4):211-216.

13. Krishnam R, Vasanti D, Raghavendra J, Niranjani K, Saravana MS. Oral hygiene levels in children of tribal population of eastern Ghats: An epidemiological study. J Int Oral Health. 2015;7(7):108-110.

14. Anupriya S, Pradeep B, Ashoo G, Suresh S, Ashish S. Oral health status and treatment needs among primary school going children in Nagrota Bagwan block of Kangra, Himachal Pradesh. J Indian Soc Periodontol. 2014;18(6):762-766.

15. Składnik-Jankowska J, Kaczmarek U. Periodontal status in children and young adults from Lower Silesia region. Dent Med Probl. 2013;50(2):167-177.

16. Dini EL, Foschini AL, Brandao IM. Periodontal conditions in a 7-19-year-old student population in Araraquara, São Paulo, Brazil, 1995. Cad Saude Publica. 1997;13(3):321-324.

17. Bossnjak A, Curilovic Z, Vuccicevic-Boras V, et al. Prevalence of gingivitis in 6- to 11-year-old Croatian children. Eur JMed Res. 2003;8(7):313-317.

18. Varenne B, Petersen PE, Ouattara S. Oral health status of children and adults in urban and rural areas of Burkina Faso, Africa. Int Dent J. 2004;54(2):83-89.

19. Banach J. Periodontal status and periodontal treatment needs among children and adolscents in 1987 and 1995 [in Polish]. Przegl Stom Wieku Rozw. 1996;2:34-38.

20. Chłapowska J. The condition and periodontal treatment needs in 7-year-olds living in the Poznań voivodeship [in Polish]. Przegl Stom Wieku Rozw. 1998;1:18-22.

21. Pawlaczyk-Kamieńska T. Selected factors of the biotope of the oral cavity in children with tendency to dental plaque mineralization [PhD dissertation]. Poznań, Poland: Poznan University of Medical Sciences;2005.

22. Gopinath VK, Rahman B, Awad M. Assessment of gingival health among school children in Sharjah, United Arab Emirates. Eur J Dent. 2015;9(1):36-40. 